\title{
Perkembangan Pemasaran Home Industri Krupuk Seblak Dan Mie Seblak Melalui Instagram dan Whatsapp Di Kelurahan Patokan Kecamatan Kraksaan Kabupaten Probolinggo
}

Alvan Fathony ${ }^{1}$, Siti Rokaiyah ${ }^{2}$, Sofiyatul Mukarromah ${ }^{3}$, Saida Salsabila ${ }^{4}$, Fitriyah ${ }^{5}$, Vina Yuli habsari ${ }^{6}$, Riza Nur Aini ${ }^{7}$, Dewi Susilowati ${ }^{8}$, Laili Fauziah Aziz ${ }^{9}$

Universitas Nurul Jadid

\{emailauthor@institution.ac.id ${ }^{1}$, sitirokaiyahrenist@gmail.com², sofiatul2575@gmail.com³, saidasalsabilla@gmail.com, fitriyahdamayanti1001@gmail.com, fideliaputri19@gmail.com, rizanuraini2008@gmail.com, dewisusilowati131@gmai.com, lellizizi01@gmail.com ${ }^{9}$ \}

\begin{tabular}{l} 
Submission: 20/12 \\
\hline Keywords: \\
Home industri, \\
Instagram, \\
Whatsapp
\end{tabular}

Katakunci: Home industri, Instagram, Whatsapp
Abstract. The current development of Information and Communication Technology has had a huge impact on all aspects of life, including business and education. Technology has become a reliable strategy in a business. Business actors usually use technology for various things. Able to get information, share information, as a means of communication between business actors, as a place to buy and sell, and so on. The purpose of this research is to identify various online marketing models through Instagram and Whatsapp in the development of home industry products in Kraksaan Probolinggo. Identification of the types of products, tools, materials and processing methods is carried out through surveys, assistance and documentation. The results of product development and online marketing that the team focused on were 2 processed variations, namely seblak chips and seblak noodles. Marketing through Instagram and Whatsapp is very helpful in spreading products and sales can increase. Activities that have been carried out are in the form of improving product quality, increasing added value, using packaging, and labeling the product. And how to market via Instagram and Whatsapp. Based on observations, the public has gained knowledge and technology related to promotional techniques through Instagram and Whatsapp.

Abstrak. Perkembangan Teknologi Informasi dan Komunikasi saat ini telah memberi pengaruh yang sangat besar bagi seluruh aspek kehidupan, termasuk dunia bisnis dan pendidikan. Teknologi telah menjadi suatu strategi yang handal dalam sebuah bisnis. Pelaku usaha biasanya memanfaatkan teknologi untuk berbagai hal. Bisa untuk mendapatkan informasi, berbagi informasi, sebagai alat komunikasi antar pelaku usaha, sebagai tempat jual beli, dan sebagainya. Tujuan penelitian ini adalah untuk mengidentifikasi berbagai model pemasaran online melalui Instagram dan Whatsapp dalam pengembangan produk home industri di Kraksaan Probolinggo. Identifikasi jenis produk, alat, bahan serta metode pengolahan dilakukan melalui survey, pendampingan dan 
dokumentasi. Hasil pengembangan produk dan pemasaran online yang tim fokuskan pada 2 variasi olahan yaitu kripik seblak dan mie seblak. Pemasaran melalui Instagram dan Whatsapp ini sangat membantu dalam menyebarluaskan Produk dan penjualan bisa meningkat. Kegiatan yang telah dilakukan berupa peningkatan kualitas produk, peningkatan nilai tambah, pemakaian kemasan, dan pemberian label produk tersebut. Dan cara pemasaran melalui Instagram dan Whatsapp. Berdasarkan pengamatan, masyarakat telah mendapatkan pengetahuan dan teknologi berkaitan dengan teknik promosi melalui Instagram dan Whatsapp.

\section{Pendahuluan}

Perkembangan Teknologi Informasi dan Komunikasi saat ini telah memberi pengaruh yang sangat besar bagi seluruh aspek kehidupan, termasuk dunia bisnis dan pendidikan. Teknologi telah menjadi suatu strategi yang handal dalam sebuah bisnis. Pelaku usaha biasanya memanfaatkan teknologi untuk berbagai hal. Bisa untuk mendapatkan informasi, berbagi informasi, sebagai alat komunikasi antar pelaku usaha, sebagai tempat jual beli, dan masih banyak lagi (Shiratina, Indika, Komariyah, Kania, \& Solihin, 2020).

Adanya musibah besar pada tahun 2019 berpengaruh bagi aspek kehidupan, termasuk bagi dunia industri. Banyak perusahaan pailit yang mengakibatkan beberapa karyawan harus di PHK (Pemutusan Hubungan Kerja). Usaha rumahan atau bisa disebut dengan istilah home industri saat ini menjadi penolong bagi mereka yang terdampak Covid'19 (Maulidasari \& Damrus, 2020). Pelaku usaha yang berbasis rumahan biasanya keluarga itu sendiri. Mereka akan mengajak beberapa sanak keluarga untuk ikut bergabung dalam usahanya. Jika usahanya sukses atau bisa dikatakan berjalan dengan lancar, mereka akan merekrut beberapa tetangga untuk dijadikan karyawan. Secara tidak langsung kegiatan home industri ini membantu pemerintah dalam mengurangi angka pengangguran. Istilah home industry atau industri rumah tangga adalah tempat tinggal yang dirangkap dengan tempat usaha, baik itu berupa usaha dibidang jasa, bidang perdagangan, dan lain sebagainya (Asse, 2018).

Dalam kegiatan industri rumah tangga biasanya memusatkan tempat kegiatan tidak jauh dari tempat tinggal karyawannya, hal ini dilakukan agar terjalin komunikasi yang erat antar pemilik usaha dan karyawannya. Karena kemungkinan besar jika rumah mitra dan rumah karyawan berdekatan, akan 
muncul rasa saling memiliki usaha yang dijalankannya (Wahyujatmiko \& Yon Hadi, 2018).

Banyak potensi yang dimiliki Indonesia saat ini, termasuk sumber daya alam yang belum dikembangkan secara maksimal dibidang kuliner. Perlu kiranya diupayakan pengembangan terhadap produk-produk yang berkaitan dengan sektor kuliner tersebut (Purwanti, Irawan, \& S, 2017). Sebagian besar wisatawan selalu menyempatkan diri untuk mampir sejenak untuk mencicipi makanan dan minuman di wisata yang biasanya terkenal kulinernya. Kuliner sendiri yaitu hasil olahan berupa masakan, masakan tersebut berupa lauk pauk, makanan dan minuman (Nisa, Laili, Qolbiyatul, \& Suyanto, 2018).

Usaha kuliner atau makanan di Kota Kraksaan saat ini perkembangannya sangat pesat. Ditandai dengan banyaknya industri rumah tangga yang memproduksi makanan yang hampir sama. Penjual berlombalomba untuk mencari kreasi dan inovasi terhadap produknya agar banyak diminati oleh konsumen (Sarastuti, 2017). Konsumen biasanya membeli makanan karena penasaran dengan varian produk terbaru yang mungkin sudah diinovasi oleh produsen. Entah itu kemasan, penyajian produk, varian rasa dan sebagainya. Saat ini banyak orang tertarik untuk menjalankan usaha rumahan karena perkembangan yang pesat ini (Basuki Cahyono, Dheasey Amboningtyas, Andi Tri Haryono, 2018).

Bagi mereka yang bekerja disebuah industri berskala menengah keatas akan menuntut untuk melakukan pekerjaan rumah dengan cepat, terutama dalam hal menyajikan makanan. Mereka akan mencari makanan yang cepat saji ataupun kuliner yang bisa dipesan dengan cepat, karena mereka tidak mau waktunya terbuang sia-sia (Supradono, 2017). Banyak makanan yang tersedia saat ini mulai dari fresh food, junk food, sampai fast food mulai dari harga murah sampai dengan mahal, mulai dari lokasi dekat sampai yang jauh sekalipun, semua sesuai selera konsumen. Penyajian dan pengelolaan dalam industri rumah tangga sudah bisa dikatakan cukup efektif, karena mereka juga sudah memperhatikan kebersihan baik tempat produksi maupun barang yang di produksi, gizi yang terkandung, dan sebagainya (Putri, 2016).

Salah satu industri makanan yang merupakan home industri yang tim pengabdian lakukan dalam skala kecil ialah mie seblak dan seblak kering 
kerupuk. Seblak memiliki dua jenis yaitu seblak basah dan kering. Seblak basah dibuat dengan menggunakan kuah pedas dengan aroma yang khas. Varian seblak basah tidak hanya mie dan kerupuk saja melainkan banyak topping yang bisa digunakan sebagai pelengkap seperti ceker ayam, sosis, bakso dan macaroni. Sedangkan seblak kering adalah terdapat beberapa variasi jajanan yang dapat dinikmati sebagai cemilan dengan rasa pedas dan renyah. Dari keduanya sama-sama menggunakan bahan dasar kerupuk (kerupuk udang atau kerupuk bawang).

Penyajian seblak basah adalah kerupuk yang dimasak dengan cara direndam terlebih dahulu sampai terlihat lembek dan terasa kenyal dimakan. Seblak kering penyajiannya sedikit agak mirip dengan seblak basah namun seblak kering kerupuk direndam menggunakan minyak goreng dingin dan di diamkan kurang lebih 30 menit agar kerupuk yang direndam tidak mengembang saat proses penggorengan.

Tim pengabdian ini memilih salah satu usaha yang memproduksi mie seblak dan seblak kering kerupuk yaitu Sdr Saida Salsabila yang terletak pada Desa Kandangjati Kulon RW 03 RT 03 Kraksaan Kabupaten Probolinggo. Kami ingin mengembangkan produk home industry yang Sdr Saida lakukan dengan memasarkan produksinya melalui Instagram, selama ini pelaku home industry hanya memasarkan produksinya melalui media Whatsaap.

Kemajuan teknologi informasi dan komunikasi khususnya internet membawa kita pada perubahan mendasar dalam kehidupan manusia. Keberadaan internet dapat memberikan kemudahan bagi siapa pun yang ingin memperoleh informasi dengan mudah dan dimana pun mereka berada. Seiring perkembangan internet yang semakin pesat, memberikan dorongan bagi pelaku usaha untuk menggunakan internet sebagai sarana dalam memasarkan produksinya.

Berbagai kebutuhan konsumen dalam kesehariannya seperti makanan dan minuman, kebutuhan rumah tangga dan lain-lainnya telah disediakan. Konsumen tidak lagi harus keluar rumah apabila ingin mencari barang dan jasa yang dibutuhkannya, karena semuanya dapat diakses atau dibeli melalui media sosial.

Bermunculannya berbagai aplikasi media sosial ini menimbulkan peluang bagi masyarakat dalam melakukan suatu usaha. Peluang terhadap 
media sosial tidak berhenti hanya pada usaha produk. Usaha jasa maupun pariwisata juga mulai menggunakan media sosial sebagai salah satu sarana untuk menarik perhatian masyarakat untuk menggunakan atau mendatangi destinasi objek wisatanya. Penggunaan media sosial digunakan oleh masyarakat dalam melakukan banyak aktivitas mulai dari entertainment, melakukan bisnis, mencari info atau aktivitas lainnya.

Ada banyak sekali macam-macam media sosial, namun yang paling diminati oleh kaum milenial saat ini yaitu Social Networking yang mana situs jejaring sosial yaitu penggunanya membentuk jaringan pertemanan baru. Dalam banyak kasus, terbentuknya jaringan pertemanan baru ini berdasarkan pada ketertarikan dengan hal yang sama, seperti kesamaan hobi. Contoh dari jaringan sosial adalah Facebook, Instagram dan Whatsapp.

\section{Metode}

Penelitian ini dilaksanakan selama 4 bulan yaitu bulan Januari hingga April 2021, di Desa Kandangjati Kulon RW 03 RT 03 Kraksaan-Probolinggo. Metode yang digunakan dalam kegiatan ini adalah melalui pendampingan. Dalam pelaksanaan kegiatan pengabdian kepada masyarakat ini, tahapan pelaksanaan kegiatan meliputi:

a. Tahapan Persiapan

Tahap persiapan ini dimulai dengan 8 orang anggota berkumpul di musholla kampus UNUJA untuk berdiskusi apa yang akan dilakukan seminggu kedepan, dimulai mebagi uang iuran untuk membeli bahanbahan dan menyiapkan segala peralatan yang dibutuhkan. Selanjutnya tim berkoordinasi dengan LP3M Universitas Nurul Jadid dan instansi terkait koordinasi dan pengurusan izin pelaksanaan kegiatan serta meyepakati tanggal pelaksanaan. Pada tahap pesiapan ini, tim melakukan penyiapan sarana prasaran pelaksanaan kegiatan seperti peralatan standar minimal yang dimiliki oleh mitra sasaran dalam pengembangan usaha. 
b. Tahap Pengembangan Produksi

Pengembangan produksi ini diberikan kepada kelompok mitra dimulai dari pemilihan bahan baku olahan dan pelatihan cara pengolahan kripik seblak dan mie seblak. Kegiatan ini bersifat aktif dengan melibatkan peran mitra dalam proses pengolahan produksi. Materi dalam pelatihan ini diberikan kepada setiap peserta pelatihan untuk mempermudah peserta mencoba mengulang kembali secara mandiri sesuai dengan panduan materi yang diberikan.

c. Pelatihan Mendesain Kemasan dan Pemasaran

Pada pelatihan ini, kelompok mitra diberikan pelatihan mendesain kemasan produk olahan bernilai jual sehingga kemasan memiliki daya tarik untuk dijual disamping kemasan dapat difungsikan untuk pengawetan makanan. Setelah pelatihan pengemasan, kelompok mitra diberikan keterampilan memasarkan produk hasil olahan melalui Instagram dan Whattsup kepada konsumen agar usaha yang dikembangkan ini dapat berkelanjutan.

d. Pendampingan

Setelah pelatihan dilaksanakan, kelompok mitra didampingi sampai pada tingkat terampil. Target dari pendampingan yang dilakukan kepada kelompok mitra adalah:

1. Mitra telah terampil mengolah produk ikan teri dan berinovasi dengan produk olahan sehingga mampu memodifikasi olahan dengan rasa yang khas.

2. Mitra telah memiliki desain kemasan yang khas dan menjadi ciri produksi olahan mitra.

3. Mitra telah memiliki pasar yang menampung hasil olahan mitra

4. Mitra telah memiliki administrasi dan pembukuan yang diterapkan pada pengelolaan ikan teri.

Analisis data dilakukan untuk menjawab permasalahan penelitian, dengan pendekatan berupa analisis deskriptif untuk menggambarkan jenisjenis produk olahan seblak yang dihasilkan di berbagai kabupaten/kota di probolinggo. Analisis deskriptif, untuk menggambarkan proses pengolahan, pengemasan dan penyajiannya serta alat dan bahan yang digunakan. 


\section{Hasil}

Jurnal pengabdian ini memuat publikasi hasil kegiatan selama pembuatan seblak. Dimulai dari pengumpulan iuran kepada setiap mahasiswi sebesar Rp 15.000 dan dari hasil tersebut didapat sebesar Rp. 120.000 yang nantinya akan dibelikan bahan-bahan dalam pembuatan seblak. Sebelum itu, juga melakukan observasi tempat yang cocok untuk melakukan kegiatan tersebut, dimana akhirnya kami diberi izin untuk menempati salah satu rumah yang kebetulan kosong dan tidak ditempati oleh pemilik rumah tersebut.

Seminggu sebelum melakukan kegiatan, tepatnya pada tanggal 22 maret 2021, kami anggota tim yang berjumlah 8 orang berkumpul di musholla kampus UNUJA untuk berdiskusi apa yang akan dilakukan seminggu kedepan, dimulai mebagi uang iuran untuk membeli bahan-bahan dan menyiapkan segala peralatan yang dibutuhkan.

Tepat 1 hari sebelum melakukan kegiatan, yaitu pada tanggal 27 maret 2021, bahan-bahan sudah terkumpul, dan melakukan beberapa persiapan peralatan dirumah yang akan di tempati. Minggu, 28 maret 2021 kami berkumpul dirumah salah satu tetangga teman kami yang berlokasi di Desa Kandangjati Kulon RW 03 RT 03 Kraksaan-Probolinggo dan telah siap untuk membuat produk seblak yang terdiri dari kerupuk seblak dan mie seblak. Semua kegiatan berjalan dengan lancar, dan hasil dari produk yang kami kerjakan sangat memuaskan.

Tim berharap dengan adanya kegiatan ini dapat menjadi inspirasi bagi teman-teman yang ikut andil dalam pembuatan seblak, dan sebagai penambah semangat dalam melakukan kegiatan promosi selanjutnya.]

\section{Pembahasan}

\section{Tahap Pelaksanaan Kegiatan}

Pada tahap ini kegiatan yang dilakukan adalah pengolahan ikan teri dengan varian rasa yang diikuti oleh 15 mitra ibu rumah tangga. Peserta kegiatan adalah ibu-ibu rumah tangga yang tinggal di pesisir pantai Grinting Desa Karanganyar yang sebelumnya sudah pernah mengolah ikan teri yang sudah dipaparkan di atas. Agenda dalam kegiatan ini antara lain: 
a. Mempersiapkan komposisi bahan utama pembuatan krupuk seblak yang terdiri dari:

- $\quad 1 / 2$ kg kerupuk bawang

- Seukupnya cabe

- Cabe bubuk / Bon cabe

- Secukupnya bawang merah dan bawang putih

- Penyedap rasa (bisa masako atau royco)

- Kencur

- Daun jeruk

- Minyak sayur

Cara Pembuatan :

- Rendam kerupuk selama kurang lebih 30 menit didalam minyak sayur yang dingin dan belum dipanaskan.

- Setelah proses diatas, nyalakan kompor dengan api kecil. Tunggu sampai kerupuk mengembang.

- Sambil menunggu kerupuk mengembang, siapkan bumbu tumis boleh diblender/ulek.

- Tumis bumbu dan berikan daun jeruk, kemudian oseng bumbu hingga tercium bau harum.

- Setelah selesai menyiapkan bumbu dan proses penggorengan kerupuk, langkah selanjutnya ialah masukkan kerupuk kedalam toples yang akan dicampur dengan bumbu dan bubuk cabe/bon cabe, kocok hingga merata. Kemudian tes rasa.

- Kerupuk seblak siap di masukkan kedalam kemasan. 


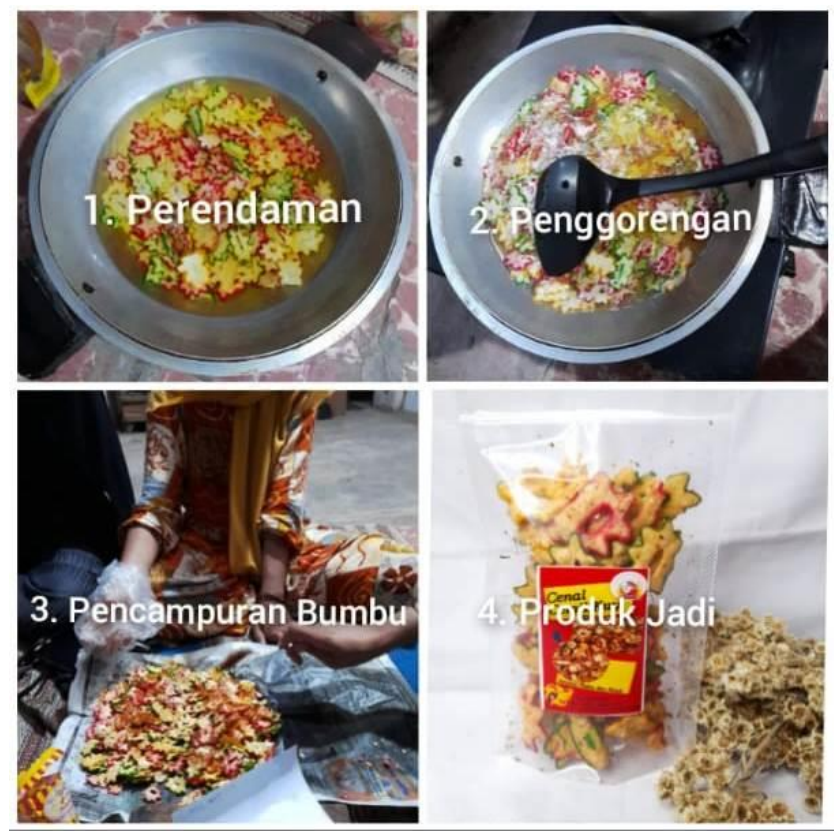

Gambar 1. Proses pembuatan kripik seblak

b. Mempersiapkan komposisi bahan utama pembuatan mie seblak yang terdiri dari:

- 100 gram kerupuk (saya pakek kerupuk udang)

- 1 butir telur

- 1 bungkus mi (saya pakek intermie)

- 1 kepal daun sawi

- 1 buah sosis (potong-potong)

- 1 tangkai daun bawang iris

- Bumbu halus

- 5 siung bawang merah

- 3 siung bawang putih

- 3 buah cabe merah

- 10 buah cabe rawit (sesuai selera)

- 2 ruas kencur

- Secukupnya garam, gula, dan penyedap rasa

- Secukupnya minyak untuk menumis 
Cara pembuatan :

- Rendam kerupuk memakai air biasa, jangan terlalu lama.

- Haluskan semua bumbu

- Panaskan minyak di wajan, masukkan telur lalu orak arik sampai hancur, masukkan bumbu yang sudah di haluskan, garam, gula, dan penyedap rasa, tambahkan sedikit air.

- Masukkan semua bahan, lalu beri air secukupnya

- Tes rasa, dan tunggu hingga matang. (kerupuk dan mi jangan terlalu matang).

- Setelah matang tuangkan pada mangkok dan siap di hidangkan.

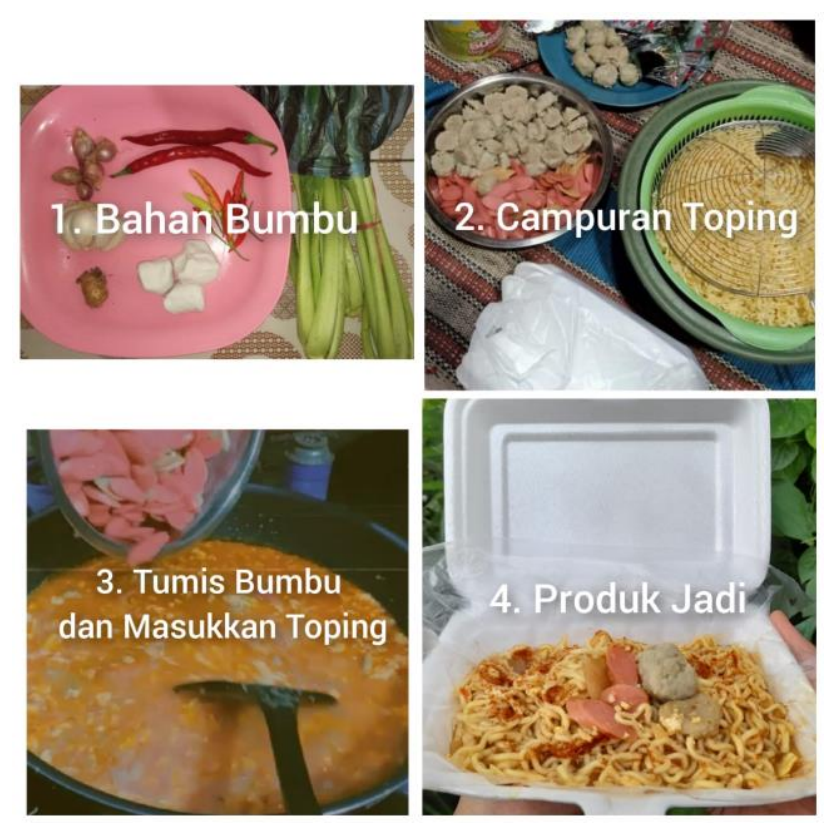

Gambar 2. Proses pembuatan seblak mie 


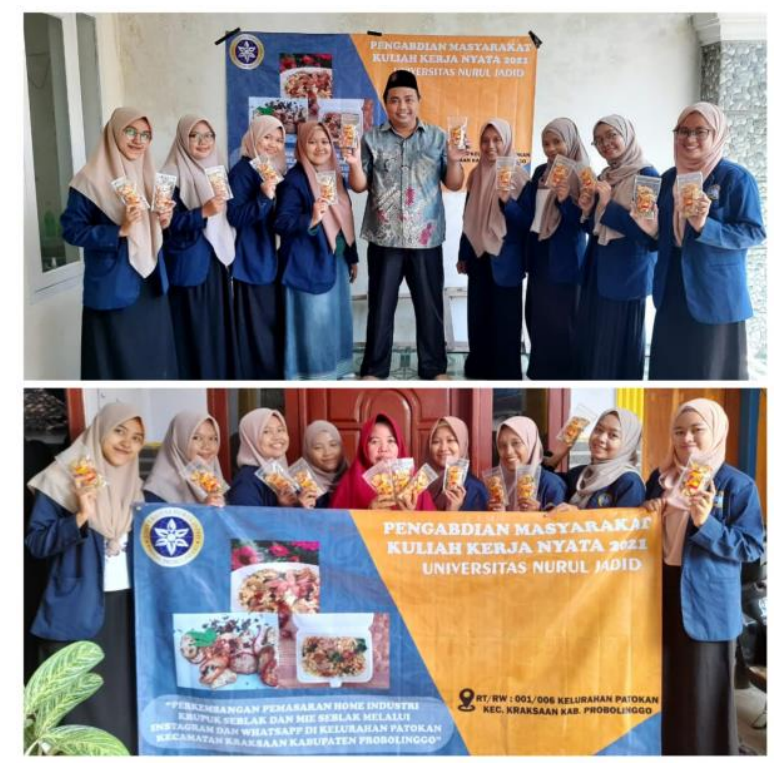

Gambar 3, foto tim bersama mitra
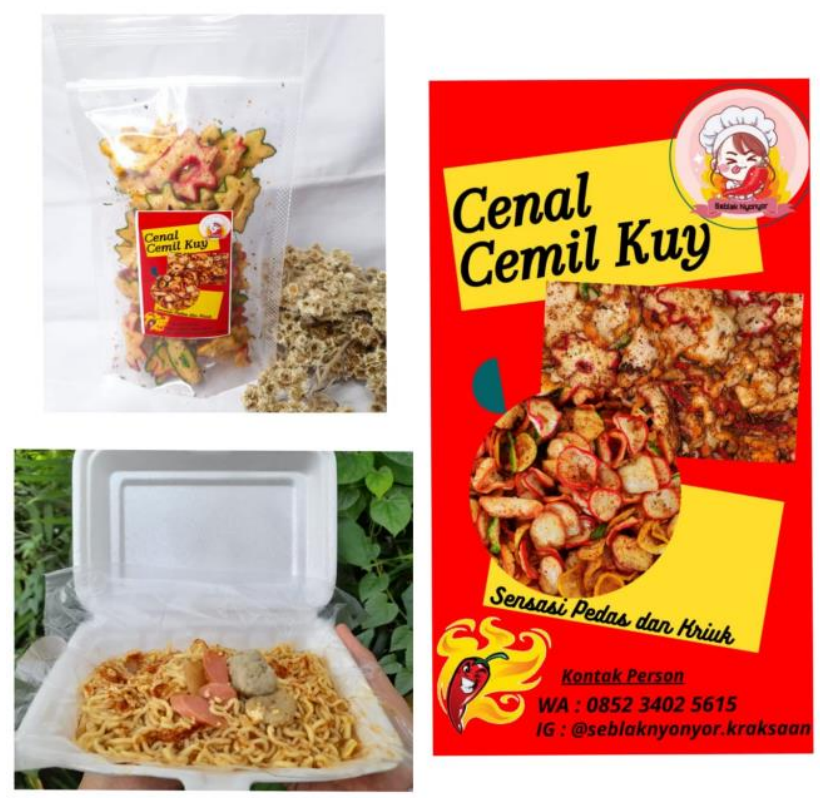

Gambar 4, foto hasil olahan 


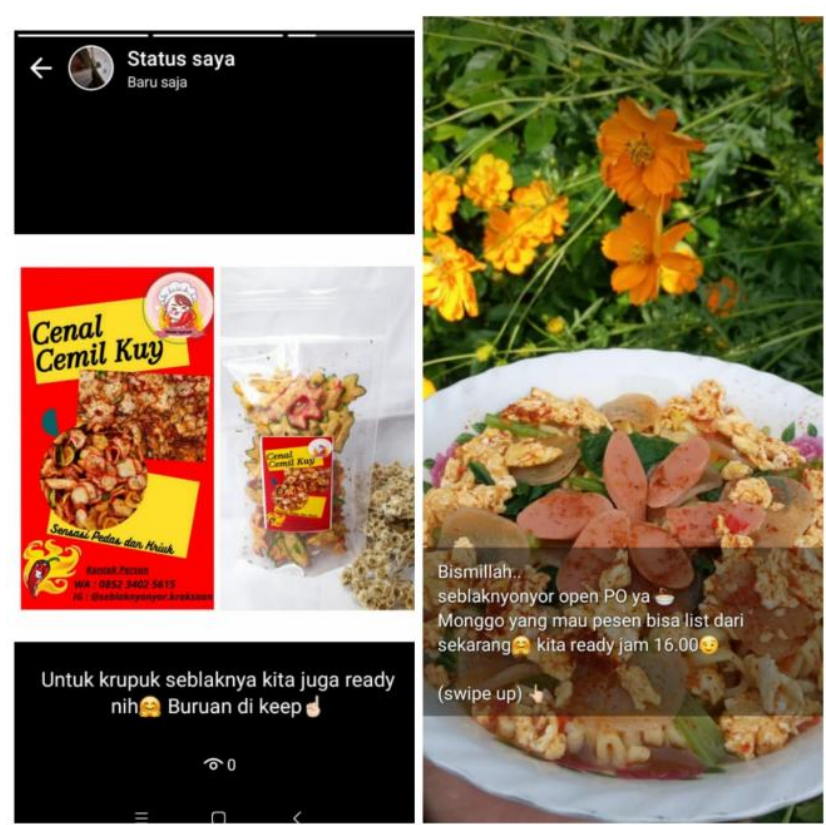

Gambar 5, promosi produk lewat Whatsapp
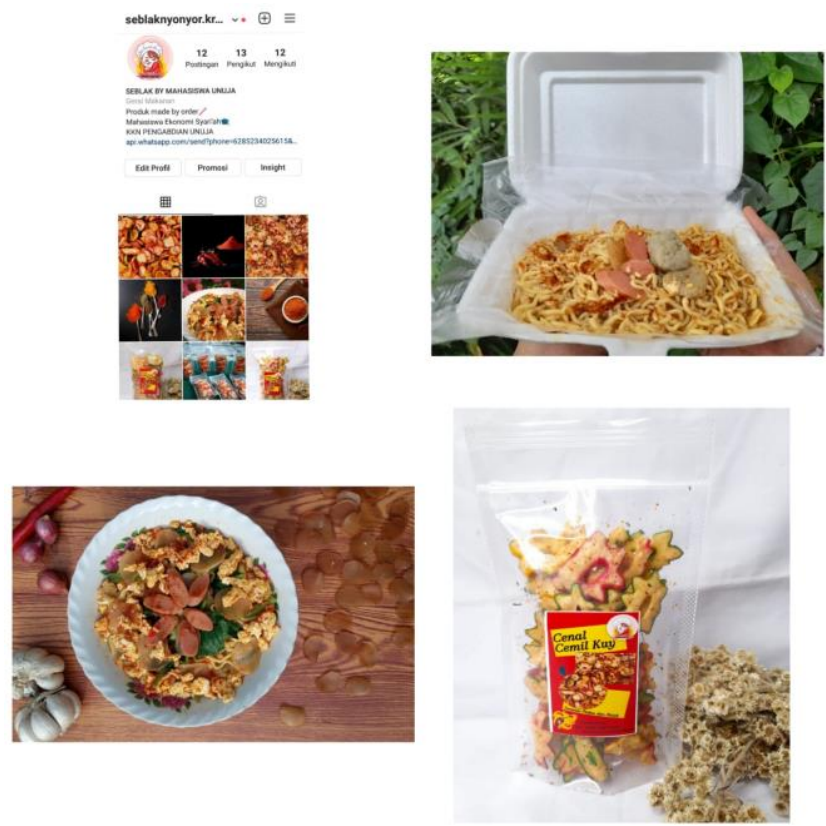

Gambar 6, promosi produk lewat Instagram

\section{Kesimpulan}

Kegiatan pendampingan home industri dalam mengelola bahan dasar seblak dengan memiliki variasi olahan dapat berjalan dengan baik dan lancar. Home industri yang terdiri dari Ibu-ibu rumah tangga sangat aktif 
dan bersemangat dalam mengikuti kegiatan sampai selesai. Para ibu-ibu setelah mengetahui dan memahami cara pembuatannya, mereka bertekad dan bersemangat untuk mencoba mempromosikan produk melalui instagram dan whattsup, dengan harapan dapat meningkatkan pendapatan home industri rumah tangga tersebut.

\section{Referensi}

Asse, R. A. A. (2018). Online Marketing Strategy (Case Study of Facebook Marketing Warunk Bakso Mas Cingkrank in Makassar). Jurnal Komunikasi KAREBA, 7(2). Retrieved from https://journal.unhas.ac.id/index.php/kareba/article/view/6907/3819

Basuki Cahyono, Dheasey Amboningtyas, Andi Tri Haryono, D. M. (2018). Analisa Kekuatan Strategi Pemasaran Melalui Online Marketing, Ofline Marketing dan Service Excellent Terhadap Loyalitas Konsumen PT Adinata Graha Raya Kaliwungu dengan Kepuasan Konsumen Sebagai Variabel Intervening. Marketing, 2(1), 1-13.

Maulidasari, C. D., \& Damrus. (2020). Dampak Pemasaran Online Di Era Covid-19. Jurnal Bisnis Dan Kajian Strategi Manajemen, 4(2), 233-245. Retrieved from http://jurnal.utu.ac.id/jbkan/article/view/2620

Nisa, K., Laili, A., Qolbiyatul, S., \& Suyanto, M. (2018). Strategi Pemasaran Online dan Offline. Abdikarya: Jurnal Karya Pengabdian Dosen Dan Mahasiswa, 1(1), 55-60.

Purwanti, N., Irawan, B., \& S, S. (2017). Eksplorasi Faktor-Faktor Online Marketing Yang Memengaruhi Keputusan Konsumen Dalam Belanja Online Pada Naufal Bag Collection. E-Journal Ekonomi Bisnis Dan Akuntansi, 4(1), 84. https://doi.org/10.19184/ejeba.v4i1.4597

Putri, N. A. (2016). Desain Strategi Pemasaran Online Pada Fullus Fashion. Jurnal Manajemen Dan Start-Up Bisnis, 1(1), 118-127.

Sarastuti, D. (2017). Strategi Komunikasi Pemasaran Online Produk Busana Muslim Queenova. Visi Komunikasi, 16(1), 71-90. Retrieved from www.queenova.com,

Shiratina, A., Indika, D. R., Komariyah, I., Kania, D., \& Solihin, E. H. (2020). Pemasaran Online Melalui Penerapan Iklan Secara Digital. Jurnal Sain 
Manajemen, 2(1), 15-23.

Supradono, B. (2017). Strategi Pemasaran Lewat Internet (Cybermarketing). Unimus, 2(3), 295-316.

Wahyujatmiko, S., \& Yon Hadi, I. (2018). Manajemen Pemasaran Online Makaroni Huhhah Yogyakarta. JBTI: Jurnal Bisnis Teori Dan Implementasi, 9(2), 100-120. https://doi.org/10.18196/bti.92104 